Alexia Hudson

\title{
Eldercare and aging \\ Online information for librarians and caregivers
}

W hile the American public, politicians, and pundits locked horns this year during the hotly debated national discussion on healthcare reform, the dialogue took a passionate (and sometimes ugly) turn at the mention of alleged "death panels for Grandma"understandably so as eldercare in America is one of the country's most challenging and emotional topics with long-reaching impact both socially and economically.

Nearly 120 million Americans (six out of every ten adults) are either providing, or have provided, unpaid care for an elderly loved one. Approximately two-thirds of the American public recently surveyed expect to be caregivers of elderly family members or friends in the future. ${ }^{1}$ The number of individuals engaged in some form of eldercare is expected to sharply increase as longevity in living continues to become the norm.

According to a June 2009 population estimate from the U.S. Census Bureau, the world's population of individuals aged 65 and older will triple from 516 million in 2009 to 1.53 billion in 2050. In the United States, 89 million Americans will be aged 65 and older by 2050 up from 39 million today. ${ }^{2}$

News of the growing elderly population can actually be viewed as good news for the academic library's reference desk. In addition to positioning ourselves as a resource for eldercare with our teaching faculty and campus administration peers, we are also in the best position to facilitate a smooth transition of older adult students onto our campuses. The American Council on Education's 2007 report "Framing New Terrain: Older Adults and Higher Education" suggests that older adults' interest in "encore careers" (careers pursued and developed after retirement) will lead many of them back into higher education. ${ }^{3}$ Our responsibility is to ensure that we are prepared to understand and address the unique concerns of older adults that may or may not be course related.

However, the cost of lost work-related productivity due to eldercare can become economically devastating for employers. U.S. businesses lose an estimated $\$ 17.1$ billion to $\$ 33.6$ billion per year in lost productivity from employees with caregiving responsibilities. ${ }^{4} \mathrm{~A}$ large portion of this lost productivity is linked to individuals seeking eldercare information and resources during their working hours.

Some of us understand from first-hand experience how eldercare impacts our ability to perform at work. As a part of the "sandwich generation," we share with colleagues our struggle in balancing job performance, marriages/partnerships, childcare, requirements on the tenure track, and active participation in professional associations with caring for elderly family members. On top of that, many of us are our families and friends "personal librarian" and have (or will in the future) field questions about eldercare resources. In that respect, creating this list was deeply personal.

My mother spent ten years taking care of my grandmother who died earlier this year.

Alexia Hudson is reference and instruction librarian at the Pennsylvania State University Abington College, e-mail: aih3@psu.edu

○ 2009 Alexia Hudson 
Her frustration with locating quality resources and centralized information on eldercare inspired this article.

\section{Associations and organizations}

- Alzheimer's Association. This site provides information and research on caring for individuals stricken with Alzheimer's disease and dementia. The education center on the homepage offers ten warning signs for Alzheimer's disease and a tour of the brain affected by the disease. The resources page provides a series of materials on music therapy, combating wandering, brain exercises, and caregiver guides. Access: http:// www.alz.org.

\section{alzheimer's $\Omega 3$ association}

- American Association for Homecare. This site gives consumer information and fact lists about homecare for the elderly. Documents on planning for long-term homecare, a home health checklist, and healthcare and Medicare definitions are readily accessible. A directory to assist in locating local home health and rehabilitation services by city and zip code is also available. The latest in medical technology for homecare is provided as a series of links to educate readers on enabling technologies to improve elderly homecare. Access: http://www.aahomecare.org.

- American Association of Retired Persons (AARP). The AARP Web site provides access to scores of online resources including AARP The Magazine, tips on travel, money management, and caregiving. A health encyclopedia, along with other online tools such as a longevity and retirement fund calculators, is easily accessible on the home page. Video, audio, and print news streams are available to educate individuals on timely

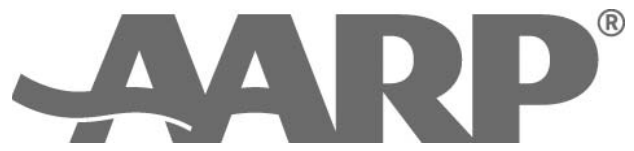

topics of interest, including how to use social networking technology, and the appropriate age to begin receiving Social Security benefits. Access: http://www.aarp.org/.

- American Geriatrics Society (AGS) AGS is a professional organization of 6,700 health care professionals. The AGS Web site serves as research repository that supplies information on careers in geriatrics, free articles on the specialized care needs of the elderly, and a free online newsletter, "AGS Week in Review." AGS also tracks and provides opinion pieces from qualified experts on advocacy and pending legislation impacting the elderly. Access: http://www. americangeriatrics.org/.

- American Society on Aging (ASA). ASA is a multidiscipline organization that focuses on improving the quality of life for older adults and their family members. The resources page offers information on mental health, lifelong learning, motor vehicle safety, and how to encourage civic engagement among the elderly population. How-to guides and articles cover topics such as injury prevention, assistive technologies, and how to address challenges of servicing the elderly within various faith-based communities. $A c$ cess: http://www.asaging.org/resources/.

- Helping People Meet Aging-Related Legal and Care Challenges (H.E.L.P.). This site gives information on issues of concern that impact the elderly such as reverse mortgages and how to avoid scams, preventing and addressing elder abuse, records management for surviving spouses and family members, and estate administration. "H.E.L.P Is Here," a free online newsletter, is archived on the site from 2002 to the current issue. Access: www.help4srs.org.

- National Association of Nutrition and Aging Services Programs. This site offers tips and resources for food and beverage safety. A nutrition checklist on the Web site focuses on causation and prevention of issues that create poor nutrition within the aged population, including disease, tooth decay, and economic hardships. Refrigerator temperature inspection guides, hot and cold 
beverage and food holding guidelines, and food safety guides are also available. Access: http://www.nanasp.org/resourcepublications. html.

- National Council on Aging. This nonprofit advocacy group works with several organizations throughout the country to provide useful information on healthy living and financial tips. A Benefits CheckUp page lists how to find benefits older citizens qualify for through state, federal, and private organizations, including assistance to pay utilities bills, prescription drugs, and the Supplemental Nutrition Assistance Program (SNAP), which was formerly known as the Federal Food Stamp program. Access: http:// www.ncoa.org/.

- National Hospice and Palliative Care Organization. This organization consists of health care professionals who specialize in hospice and end-of-life care. The Caring Connections Web page gives information on locating a hospice, developing a living will, coping with grief, and palliative care. The site also offers a Google Health link to store and share one's advance care directives with their caregivers. Information for employers, including learning modules about caregivers in the workplace, sample leave of absence policies, and a sample employer's guide, are also available. Access: http://www.caringinfo.org/.

- National Resource Center for Safe Aging. This is a collaborative initiative between San Diego State University's Graduate School of Public Health and the College of Health and Human Services, the Centers for Disease Control and Prevention (CDC), and the CDC's National Center of Injury Prevention and Control. Podcasts on elder abuse and older drivers can be viewed and are supplemented with toolkits on preventing injuries due to falling among the elderly. Regional and national data on fatality statistics, U.S. census information, health statistics, and reports from the United States Consumer Product Safety Commission and health care costs are also housed here. Access: http:// www.safeaging.org.

\section{Academic/scholarly research centers}

- AGS Foundation for Health In Ag-

ing. This site was created by the American Geriatrics Society to create better linkages between the research of geriatrics and the general public. A checklist of what caretakers should ask healthcare providers, summaries of recent studies published in The Journal of The American Geriatrics Society (JAGS), and funding opportunities for healthcare researchers is also included. Access: http:// www.healthinaging.org/.

- Gerontological Society of America (GSA). GSA promotes both multi- and interdisciplinary research regarding the level and a high-quality of gerontological research. GSA offers three online publications_- "Ripples," the e-newsletter of the Geriatric Social Work Initiative is a mashup of internal association and external news, blogs, and research; "Public Policy and Aging" is a bimonthly newsletter that focuses on one specific topic per issue such as pensions, the fiscal impact of aging, and the impact of research on the aging brain; and "Civic Engagement," which is also a bimonthly publication that highlights programs, research, and policy to increase civic participation among older adults. Access: http://www.geron.org/Publications /E-Newsletters.

- Resource Center on Aging, University of California-Berkley. The center serves as a clearinghouse for university-related and California-based resources on aging. The site includes a listing of scholarly journals on aging, Alzheimer's Disease, dementia, legal issues, and community-based lifelong learning centers. Access: http://socrates.berkeley. edu/ aging/.

- Sloan Center on Aging and Work at Boston College. This site provides research and strategies on issues related to balancing multiple generations within the 21st-century workplace. Their issues briefs, fact sheets, and publications cover topics such as creating responsive workplaces for older workers, older worker displacement trends, and the connections between older workers and their adult children within the 
workplace. Access: http://agingandwork. bc.edu/template_index.

\section{Government resources}

- Centers for Disease Control and Prevention Healthy Aging Web site. This site is layered with information on how to create and maintain healthy living habits for seniors. Details on the "Healthy Brain Initiative" and an interactive report entitled "The State of Aging and Health in America 2007" evaluates the health status and behaviors of Americans aged 65 and older. Access: http:// www.cdc.gov/aging/.

- MedLine Plus Seniors' Health Medline Plus. This is a service provided by the U.S. National Library of Medicine and the National Institutes of Health. Links and online tutorials on topics such as alternative medicine, Medicare prescription drug coverage, and disease prevention are available. Access: http://www.nlm.nih.gov/medlineplus /seniorshealth.html.

- U.S. Department of Health and Human Services Administration on Aging. This site gives information health care reform, elder rights protection, and emergency preparedness for the elderly. A Web resources link on the homepage redirects you to the Eldercare Locator, which offers a series of fact sheets on governmental housing benefits, seniors and HIV, transportation options for older adults, and the ability to find healthcare providers by city, state, and zip code. Access: http://www.aoa.gov/ and http://www. eldercare.gov/Eldercare.NET/Public/Home. aspx.

- U.S. National Institute of Health National Institute on Aging. This site provides information on medications, supplements, conditions, and diseases. Information is also included for those interested in participating in federal and privately supported clinical trial research on bone loss, Alzheimer's disease, and diabetes medications. Access: www.nia. nih.gov.

- USA.gov Senior Citizens' Resources. This site makes locating government based resources easy in a one-stop shopping ap- proach. Education, jobs, and volunteer opportunities for older adults are listed in addition to information for caretakers and laws and regulations that impact seniors. A travel link at the bottom of the page will redirect readers to Amtrak's senior discount page. One can also subscribe to receive online updates of the site. Access: http://www.usa.gov/Topics /Seniors.shtml.

\section{Ethnogeriatrics/diversity resources}

- Ethnic Eldercare Network. This site touts itself as a "complete Internet resource for caregivers and health professionals of Ethnic Elders." Cultural beliefs about aging that impact care giving and strategies on how to combat ethnic stereotyping in health care are highlighted. Access: http://www. ethnicelderscare.net/.

- LGBT Aging Project. Created to address concerns regarding outreach, education, and advocacy for the LGBT aging community. Caregivers support and bereavement groups, health and housing information, social organizations, and networking events are continuously added to the site. Access: http://www. lgbtagingproject.org.

- National Caucus and Center on the Black Aged. This organization works to improve the quality of life for Black and lowincome minority senior citizens. The site includes detailed information about the Senior Community Service Employment Program, which assigns seniors paid part-time work at various nonprofit and community service organizations, such as libraries, hospitals, governmental agencies, and senior centers. Access: http://www.ncba-aged.org/.

- National Hispanic Council on Aging. Focusing primarily on providing assistance to Hispanic senior citizens and their families, this site includes news streams of interest to the Hispanic community. A cultural competence e-learning module for healthcare providers that addresses cultural and language barriers that prevent quality care for the Hispanic elderly. Access: http://www.nhcoa.org/.

- National Indian Council on Aging. This group provides guidelines on using 
tribal values to create an elder protection code within the National Indian population, diabetes education, and a caregiver stress fact sheets. Their "Elder Visions" newsletter is also available from 1981 to current issue on the Web site. Access: http://www.nicoa.org/.

- Segunda Juventud. AARP's bilingual online magazine provides active online community that offers games, celebrity interviews, recipes, along with video and audio casts. Access: http://www.aarpsegundajuventud.org/english/index.html.

\section{Notes}

1. "Family Caregiving in America: Facts at a Glance" Johnson and Jonson Strength for Caring: A Place for Caregivers, www.strengthforcaring.com/util/press/facts/facts-at-a-glance. html (accessed August 31, 2009).
2. "Census Bureau Reports World's Older Population Projected to Triple by 2050," www.census.gov/Press-Release/www/releases/archives /international_population/013882.html (accessed August 31, 2009).

3. Mary Beth Lankin, Laura Mullane, and Susan Porter Robinson, "Framing New Terrain: Older Adults \& Higher Education" American Council on Education (October 2007), www.acenet.edu/Content /NavigationMenu/ProgramsServices/CLLL /Reinvesting/Reinvestingfinal.pdf (accessed August 30, 2009).

4. Metlife Mature Market Institute, National Alliance for Caregiving (July, 2006). The MetLife Caregiving Cost Study: Productivity Losses to U.S. Businesses, Westport, Connecticut: MetLife Mature Market Institute. $\mathbf{n}$
("The Tech Deck," continued from page 510)

techniques for using Illustrator to make a poster. This is peer learning in action. This is the library's vision for the Tech Deck.

Over the next several months, we plan to:

- create a culture of participatory learning by training peer consultants to offer in-person and virtual assistance;

- build a peer learning community via peer-reviewed and peer-created online tutorials that are available $24 \times 7$;

- promote social networking tools designed to facilitate peer learning;

- engage faculty in specific class projects that require multimedia;

- promote access to experts via technical and process workshops (e.g., how to work efficiently in groups, best practices for visual display, how to build effective Web pages with Dreamweaver, etc.) and access to specialized software and equipment; and

- offer support in the creation of visually compelling projects (presentations, posters, Web pages, etc.).

\section{Tech Deck in action}

In an age where undergraduates have easy access to information of varying degrees of validity and complexity, it is more important than ever to promote skills that can help students find, select, and transform information into knowledge.

Coupled with the expectation that the end product is expressed not just in a traditional research paper, but rather a high-end video, poster, or multimedia format, we must develop ways to engage our undergraduates in sharing their ideas and learning from one another.

The Tech Deck provides a learning environment that is transparent and flexible in its use, a space to foster student collaboration, and a service to promote participatory learning.

As we look to the future and implement our vision for the virtual Tech Deck, our commitment to undergraduate learning remains strong and grows with the changing needs of our students.

\section{Notes}

1. MLibrary Tech Deck, www.lib.umich. edu/techdeck.

2. Knowledge Navigation Center,www. lib.umich.edu/knc. $\boldsymbol{n}$ 